\title{
Compósitos à base de cimento reforçados com polpa celulósica de bambu. Parte I: Determinação do teor de reforço ótimo
}

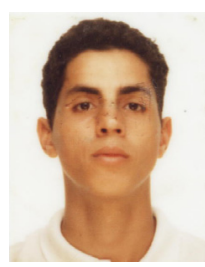

Marcos A. S. dos Anjos ${ }^{1}$, Khosrow Ghavami ${ }^{2}$ \& Normando P. Barbosa ${ }^{3}$

1 Escola Técnica Federal de Palmas. Coord. de Edificações, Av. LO 05 s/n, AESE 34, CEP 77000-000, Palmas, TO. Fone: (63) 225-1205. E-mail: malyssandro@etfto.gov.br (Foto)

2 PUC-Rio. Rua Marquês de São Vicente 225, Gávea, CEP 22453-900, Rio de Janeiro, RJ. E-mail: ghavami@civ.puc-rio.br

${ }^{3}$ CT/UFPB. CEP 58059-900, João Pessoa, PB. Fone: (83) 246-2669. E-mail: npperazzo@lsr.ct.ufpb.br

Protocolo $165-6 / 11 / 2002$ - Aprovado em 13/8/2003

\begin{abstract}
Resumo: Este trabalho apresenta os resultados experimentais de um estudo em que se procurou desenvolver compósitos de matriz cimentícia reforçada com polpa de bambu. Foram usados dois tipos de polpa: refinada e sem refino. Fez-se variar o teor de fibras de 0 a $16 \%$ em massa de cimento e se desenvolveu um processo com sucção, moldagem e prensagem para fabricação dos compósitos. As relações constitutivas dos compósitos foram definidas através de ensaio a compressão e tração de corpos-de-prova cilíndricos de $5 \times 10 \mathrm{~cm}$ e do ensaio de flexão em três pontos. A partir delas, foi obtida a capacidade de absorção de energia. Determinaram-se, também, algumas propriedades físicas, como absorção, porosidade aparente, densidade seca e úmida dos compósitos. Os resultados mostraram melhor performance dos compósitos com fibras refinadas em relação àquelas com fibras sem refino e também indicaram que o teor ótimo de fibras refinadas se situou em torno de $8 \%$, quando promoveram notáveis melhoramentos das propriedades mecânicas dos compósitos em relação à matriz plena.
\end{abstract}

Palavras-chave: compósito, fibra vegetal, polpa de bambu

\section{Cement-based composite reinforced with bamboo pulp. Part I: Determination of optimum reinforcement percentage}

\begin{abstract}
This work presents the experimental results of a study which intended to develop a composite with cementations matrix reinforced with bamboo pulp. Two types of pulps were used: refined and unrefined pulps. The fibre content varied between 0 and $16 \%$ cement (weight basis) . After the preparation of fresh composite mix the experimental specimens were prepared applying a specially developed process based on Hastshek method using suction then moulding and pressing. The compression, tension and the flexural behavior and their constitutive relations were established using $5 \mathrm{~cm}$ diameter by $10 \mathrm{~cm}$ high cylindrical specimens and three point bending tests at respectively. The energy absorbing capacity of the new composites was also established. Physical properties such as water absorption, apparent porosity, dry and humid density were also obtained. The results showed a better performance of composites with refined fibres when compared to those with unrefined ones. It was observed that the optimum fibre content was approximately $8 \%$ of refined fibre which improved the mechanical properties of the composites.
\end{abstract}

Key words: composite, vegetable fibre, bamboo pulp

\section{INTRODUÇÃO}

O cimento-amianto foi o primeiro material de construção civil reforçado com fibras naturais produzido em escala industrial. No entanto, nas últimas três décadas ele vem sofrendo sérias restrições de uso, devido à constatação de enfermidades provocadas pelas fibras de amianto, como câncer e fibrose pulmonar. Atualmente, todos os países da atual União Européia, Canadá, EUA e México, aboliram o uso do asbesto. No Brasil, a Lei Orgânica de alguns municípios já proíbe o uso de derivados de amianto e, em termos nacionais, já está em fase de discussão no Conselho Nacional de Meio Ambiente (CONAMA), a diminuição do seu emprego.

Frente à inadequação do uso do amianto para produção de materiais de construção civil sem riscos à saúde da sociedade, surge a necessidade de encontrar um substituto com propriedades físicas e mecânicas adequadas, que seja ecológico, de baixo custo e com disponibilidade local (Anjos, 2002). Os fibrocimentos com reforço de polpa de madeira são utilizados na Austrália desde 1981, em substituição ao cimento-amianto (Coutts \& Ni, 
1995). Outros países, como Suécia e Holanda, têm investido bastante em pesquisas em que se utilizam compósitos, reforçados com matéria-prima vegetal. $\mathrm{O}$ interesse está na busca de um material de baixo consumo de energia e amigável ao ambiente. O Brasil, como detentor de uma grande reserva de recursos naturais, deve adiantar-se em busca do domínio da tecnologia de produtos reforçados com fibras vegetais, visto que isto parece ser a tendência natural e mais adequada para substituição do amianto (Rodrigues, 1999).

Fibras vegetais, como reforço de matrizes frágeis à base de materiais cimentícios, devem despertar, num futuro próximo, grande interesse nos países em desenvolvimento, em função de seu baixo custo, disponibilidade e economia de energia. Segundo Swamy (1990) o emprego dos compósitos em placas, telhas de cobertura e componentes pré-fabricados pode representar significativa contribuição para o rápido crescimento da infra-estrutura desses países. No Brasil, pesquisas sistemáticas sobre o uso de materiais de baixo consumo de energia e renováveis foram iniciadas na PUC-Rio, em 1979. Hoje, várias pesquisas estão em andamento em outros centros e universidades, como UFPB, IME, USP e UNICAMP.

$\mathrm{O}$ interesse no uso de polpas celulósicas extraídas das fibras está no fato de que o processo de polpação confere remoção das impurezas não celulósicas, como a lignina e a hemicelulose, diminuindo o ataque às fibras sem a necessidade de modificações na matriz cimentícia, pois o processo de polpação tipo Kraft pode chegar a remover toda a lignina presente no material de origem (Smook, 1989).

Neste trabalho é analisado o uso de diferentes porcentagens de polpas celulósicas de bambu (variando de 4 a 16\%), com dois estágios de tratamento diferentes, quais sejam, polpas antes do processo de refino e após este processo, para reforço de matrizes cimentícias, utilizando-se o processo de produção Hatschek, em escala laboratorial. Esses teores de reforço foram empregados para análise da influência do tipo e do percentual de polpa celulósica nas características físicas, mecânicas e microestrutural dos compósitos e para determinar a percentagem de reforço ideal para produção de elementos de cobertura.

Este artigo corresponde à primeira de uma publicação em duas partes, tratando de polpa celulósica de bambu reforçando matrizes frágeis à base de cimento.

\section{MATERIAL E MÉTODOS}

Neste trabalho foi utilizado cimento Portland CP II E - 32, marca Eldorado, com massa específica de $3,09 \mathrm{~kg} \mathrm{dm}^{-3}$ e tempo de início e fim de pega de $2 \mathrm{~h} 30 \mathrm{~min}$ e $4 \mathrm{~h} 30 \mathrm{~min}$, respectivamente. O CP II E já contém, em sua constituição, de 6 a 34\% de escória de alto forno moída, proporcionando assim uma matriz com menor teor de hidróxido de cálcio, com conseqüente diminuição do ataque alcalino à lignina das fibras.

A polpa celulósica foi proveniente da fábrica de papel Itapajé, localizada no Estado do Maranhão. A Figura 1 mostra a absorção de água em função do tempo, pelas polpas refinadas e sem refino, determinada no Laboratório de Estruturas e
Materiais da PUC-Rio (LEM-PUC). Nela, também está indicada a umidade natural, $\mathrm{H}_{\text {nat }}$. A absorção foi determinada pesandose 10 gramas de polpa seca e colocando-a em $1 \mathrm{~L}$ de água. A pesagem da polpa úmida (após imersão em água) foi realizada aos 5, 20, 30 min e $1 \mathrm{~h}$, depois com acréscimos de hora em hora, até completar $6 \mathrm{~h}$, sendo pesada, após este tempo, de 24 em 24 h, até a saturação. Antes da pesagem da polpa úmida, esta era passada em uma peneira de $0,15 \mathrm{~mm}$ e espalhada em um papel absorvente para retirar a água que fica adsorvida entre as fibras. Para a determinação da absorção foram realizadas 5 repetições para cada tipo de polpa.

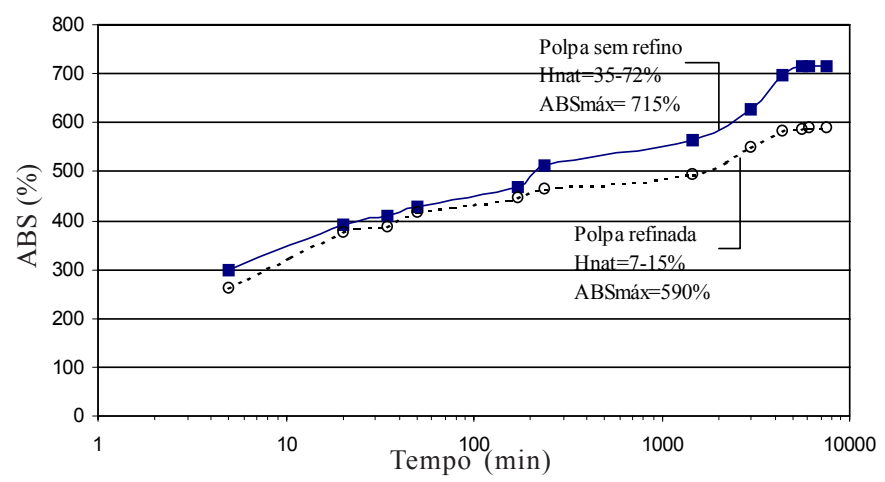

Figura 1. Absorção de água em função do tempo, pelas polpas refinadas e sem refino

\section{Processo de fabricação dos compósitos}

Para fabricação dos compósitos é necessário realizar-se, antes da mistura, uma dispersão da polpa em água, tendo em vista que a secagem e prensagem da polpa realizadas antes do transporte desde a fábrica até o laboratório, causaram aglutinação dos filamentos. Esta dispersão é realizada em um equipamento adaptado com hélice tipo centrífuga e rotação de $2.000 \mathrm{rpm}$ (Figura 2).
A.

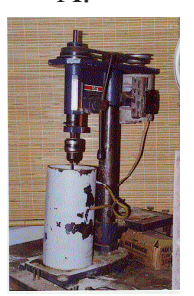

Figura 2. Dispersão das polpas aglutinadas. Equipamento de dispersão (A), polpa antes da dispersão (B) e após a dispersão (C)
A mistura dos materiais para a produção dos compósitos foi realizada com um misturador elétrico com velocidade de rotação de 500 rotações $\min ^{-1}$, com copo e hélice de aço. A mistura foi feita por $10 \mathrm{~min}$, resultando em uma pasta fluida de cimento e polpa com teores de 25 a $30 \%$ de material sólido em massa. Após a homogeneização, o material foi transferido rapidamente para a câmara de moldagem onde foi submetido a uma subpressão em sua face inferior, com o auxílio de uma bomba de vácuo, mostrada na Figura 3.

A câmara de moldagem tem dimensões de 120 x 120 mm e altura de $100 \mathrm{~mm}$. Na parte inferior há uma chapa vazada com abertura de $5 \mathrm{~mm}$ e uma tela metálica, sobre a qual são colocados 
A.

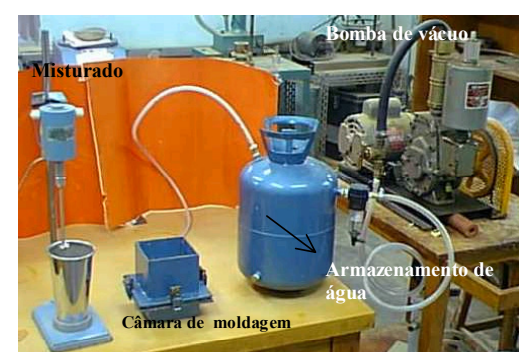

B.

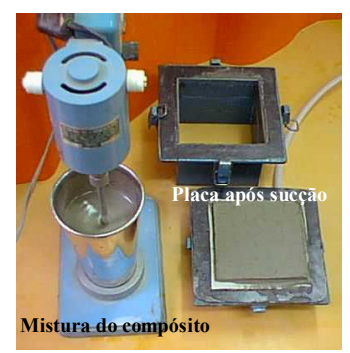

Figura 3. Equipamento e seqüência de moldagem. Equipamento de moldagem (A) e mistura, moldagem e desforma (B)

uma manta de poliéster e um filtro de papel, de forma a se poder extrair a água em excesso e evitar a perda de material sólido, como mostra a Figura 4.

A.

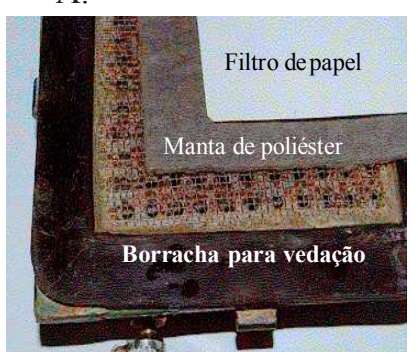

Figura 4. Câmara de moldagem. Detalhe do material de filtragem

(A) e câmara de moldagem (B)

Para diferentes percentuais de polpa $(4,6,8,10,12,14$ e 16\%) foram produzidas três placas, as quais são empilhadas e intercaladas por chapas de aço e toalhas de papel, para serem submetidas à prensagem em uma prensa hidráulica, durante $5 \mathrm{~min}$, a uma pressão constante de 3,2 MPa. A prensagem é realizada para retirar o excesso de água que restou nas placas após a sucção ou que tenha sido absorvida pela polpa. Após a prensagem, as placas foram acondicionadas em sacos plásticos durante $24 \mathrm{~h}$, para manter uma umidade constante, em torno de 90-95\%, e evitar a perda de água para o meio ambiente. Após a cura por imersão durante 6 dias, as placas foram retiradas e cortadas com uma serra circular de disco diamantado, nas dimensões finais de $36,5 \times 120 \mathrm{~mm}$. Esses corpos-de-prova foram mantidos em ambiente controlado a uma temperatura de $23 \pm$ $2{ }^{\circ} \mathrm{C}$ e umidade em torno de $50 \pm 5 \%$, até a data dos ensaios.

Espécimes cilíndricos foram moldados com o intuito de se caracterizar todo o comportamento mecânico deste material, já que não foram encontrados, na bibliográfica consultada, resultados de propriedades mecânicas, como resistência a compressão, a tração direta e a tração por compressão diametral dos compósitos reforçados com polpa celulósica e moldados pelo processo Hatschek. Para tanto, após a desforma das placas, estas foram quebradas em pedaços e colocadas dentro de um molde cilíndrico de $5 \mathrm{~cm}$ de diâmetro por $10 \mathrm{~cm}$ de altura, em quatro camadas, as quais foram adensadas com 60 golpes de um soquete metálico com diâmetro de $2,5 \mathrm{~cm}$, para homogeneizar e conferir ao material a forma cilíndrica (Figura 5). Terminada esta operação, o material recebia a mesma pressão de 3,2 MPa, que era aplicada às placas para retirar o excesso de água, como indicado na Figura 5C.
A.

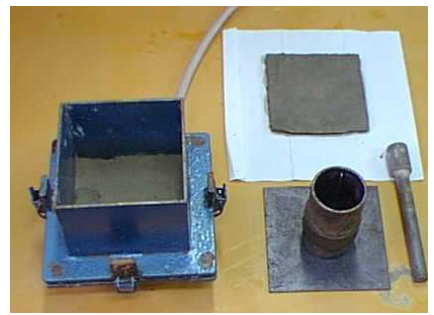

B.

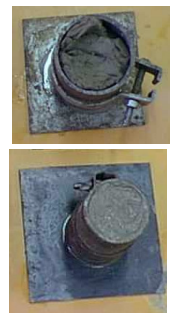

Figura 5. Moldagem de corpos-de-prova cilíndricos de 5 x 10 $\mathrm{cm}$. Desforma (A), CP antes e após os golpes (B) e prensagem do material $(\mathrm{C})$

\section{Ensaios realizados}

Propriedades físicas: as propriedades físicas determinadas neste trabalho foram densidade no estado seco $\left(\mathrm{D}_{\mathrm{s}}\right)$ e úmido $\left(\mathrm{D}_{\mathrm{h}}\right)$, absorção de água $\left(\mathrm{W}_{\mathrm{a}}\right)$ e porosidade aparente $\left(\mathrm{P}_{\mathrm{a}}\right)$, segundo recomendações do RILEM (1984). Essas propriedades foram calculadas através de relações simples entre a massa do compósito saturado, saturado submerso e seco. Os espécimes utilizados para determinação dos índices físicos foram os mesmos utilizados nos ensaios de flexão, sendo os testes realizados aos 28 dias de idade.

Microscopia eletrônica de varredura: a microscopia eletrônica de varredura foi realizada em um microscópio eletrônico da marca ZEIS, com a obtenção das imagens utilizando-se deteç̧ão de elétrons secundários com tensão de $2,0 \mathrm{kV}$. A microscopia foi executada com o intuito de se verificar o aspecto e a distribuição das fibras, dentro dos compósitos, e analisar a superfície de fratura após os ensaios de flexão.

Ensaio de flexão: os ensaios de flexão foram realizados também aos 28 dias em equipamento de três cutelos com vão livre $\mathrm{L}=100 \mathrm{~mm}$ e aplicação de carga centrada no sentido da espessura, com deslocamento de travessão constante de $0,5 \mathrm{~mm} \mathrm{~min}{ }^{-1}$ utilizando-se uma máquina de ensaio Instron $5500 \mathrm{~N}$. Os espécimes utilizados tinham dimensões de $120 \mathrm{~mm}$ de comprimento total e largura $b=36,5 \mathrm{~mm}$ com espessura $\mathrm{e}=6 \mathrm{~mm}$.

Para o cálculo da resistência máxima à flexão e do módulo de elasticidade na flexão, utilizaram-se as equações $\mathrm{f}_{\mathrm{f}}=(3 \mathrm{PL}) /$ $\left(2 \mathrm{be}^{2}\right)$ e $\mathrm{E}_{\mathrm{f}}=\left(\mathrm{mL}^{3}\right)\left(4 \mathrm{be}^{3}\right)$ respectivamente, $\operatorname{com} \mathrm{P}=$ carga máxima do ensaio antes da primeira fissura e $\mathrm{m}=$ inclinação do trecho linear da curva carga-deflexão (ASTM, 1996). A capacidade de absorver energia estática na flexão, é determinada pela área abaixo do gráfico carga versus deflexão, até o nível de carga de $40 \%$ da carga máxima (de pico) no trecho descendente, de acordo com o proposto pelo RILEM (1984).

\section{Ensaios de compressão e de tração por compressão diametral:} Foram moldados corpos-de-prova cilíndricos para a realização de ensaios de compressão e de tração por compressão diametral, para os compósitos com teor de reforço considerado ideal, determinados a partir dos ensaios de flexão. Os corposde-prova de compressão foram ensaiados de acordo com a NBR 5739 (ABNT, 1994) e instrumentados com strain gage tipo L colados a meia altura dos corpos-de-prova, para determinação das curvas tensão versus deformação axial $\left(\varepsilon_{\mathrm{a}}\right)$, lateral $\left(\varepsilon_{l}\right)$ e volumétrica $\left(\varepsilon_{\mathrm{v}}\right)$, com $\varepsilon_{\mathrm{v}}=\varepsilon_{\mathrm{a}}+2 \varepsilon_{1}$. 
Os espécimes do ensaio de tração por compressão diametral também foram instrumentados com strain gage tipo $\mathrm{L}$ e ensaiados de acordo com a NBR 7222/83 (Figura 6B).

A.
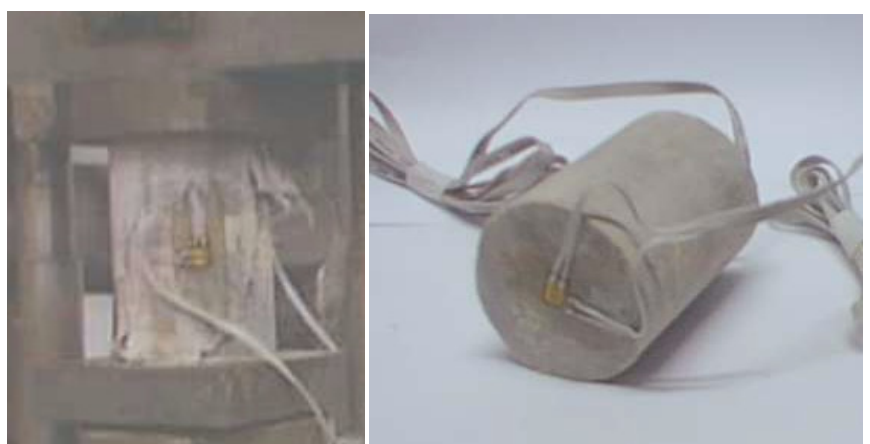

Figura 6. Instrumentação para ensaio de compressão diametral. Espécime de compressão(A) e espécime de tração por compressão diametral

\section{RESULTADOS E DISCUSSÃO}

\section{Propriedades físicas}

Absorção de água, porosidade aparente (vazios permeáveis) e densidades seca e úmida dos compósitos, são propriedades físicas inter-relacionadas e de grande importância para o uso pretendido para os compósitos, qual seja, painéis de cobertura. Verifica-se que os compósitos reforçados com polpa sem refino apresentam maior absorção de água que os compósitos com polpa refinada (Tabela 1), fato relacionado ao aspecto da fibra refinada, que apresenta uma superfície lisa e pouco danificada, em forma de fita, parecendo ser mais densa que a fibra sem refino. Esta última apresenta um aspecto mais circular e mais poroso, como pode ser visto na Figura 7B. As fibras sem refino apresentaram, em média, diâmetro de $11 \mu \mathrm{m}$; já as polpas refinadas tinham espessura de $4,5 \mu \mathrm{m}$ e largura de $9 \mu \mathrm{m}$, numa estimativa feita ao microscópio eletrônico de varredura (MEV).

Tabela 1. Propriedades físicas dos compósitos aos 28 dias e coeficiente de variação*

\begin{tabular}{ccccc}
\hline \multirow{2}{*}{$\begin{array}{c}\text { \% de } \\
\text { Fibra }\end{array}$} & AM - $\%$ & PA - \% & \multicolumn{2}{c}{ Densidade $-\mathrm{kg} \mathrm{m}^{-3}(\mathrm{CV}-\%)$} \\
\cline { 5 - 5 } & $(\mathrm{CV}-\%)$ & $(\mathrm{CV}-\%)$ & Seca & Úmida \\
\hline A. Polpa refinada & & & \\
0 & $6,5(1,2)$ & $13,1(0,8)$ & $2160(12,0)$ & $2230(11,0)$ \\
4 & $17,5(6,4)$ & $30,6(3,4)$ & $1750(2,7)$ & $2060(1,7)$ \\
6 & $20,2(10,4)$ & $33,1(5,7)$ & $1640(4,4)$ & $1970(2,7)$ \\
8 & $20,6(8,7)$ & $33,6(4,9)$ & $1640(4,0)$ & $1970(2,3)$ \\
10 & $25,8(20,5)$ & $37,7(10,3)$ & $1480(2,2)$ & $1860(5,0)$ \\
12 & $23,7(7,6)$ & $36,4(3,8)$ & $1540(3,7)$ & $1910(2,3)$ \\
14 & $25,2(4,4)$ & $37,8(2,1)$ & $1500(2,3)$ & $1880(1,4)$ \\
16 & $32,4(4,3)$ & $42,8(2,2)$ & $1320(2,1)$ & $1750(1,1)$ \\
\hline B. Polpa sem refino & & & \\
4 & $18,5(6,3)$ & $31,4(3,2)$ & $1700(3,1)$ & $2020(2,1)$ \\
6 & $23,3(4,3)$ & $36,7(2,5)$ & $1580(2,5)$ & $1940(2,0)$ \\
8 & $25,4(12,6)$ & $37,3(5,6)$ & $1480(7,0)$ & $1850(4,5)$ \\
10 & $28,2(18,2)$ & $41,5(4,3)$ & $1410(5,5)$ & $1820(3,3)$ \\
12 & $30,8(6,2)$ & $42,2(2,4)$ & $1370(3,7)$ & $1800(2,3)$ \\
14 & $33,3(8,1)$ & $43,4(4,7)$ & $1310(3,4)$ & $1740(1,4)$ \\
16 & $32,3(4,0)$ & $43,0(1,4)$ & $1330(2,7)$ & $1760(1,8)$ \\
\hline AM - Absorção em massa, PA - Porosidade aparente &
\end{tabular}

AM - Absorção em massa, PA - Porosidade aparente
A.

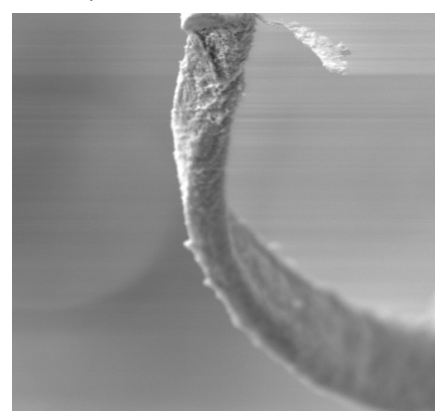

B.

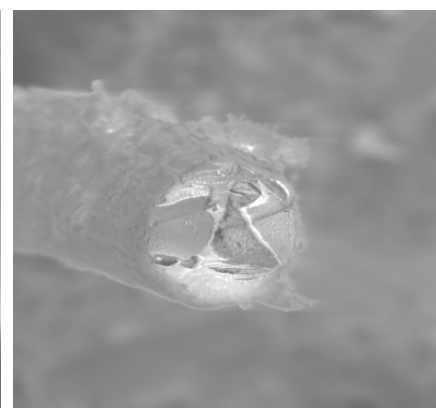

Figura 7. Imagem das fibras obtidas no MEV com aumento de 2000 vezes. Fibra refinada (A) e sem refino (B)

Como referência, à NBR 12800 estabelece que a absorção máxima em massa para telhas onduladas de fibrocimento deve ser de 37\%; com isto, absorção de água apresentada pelos compósitos deste trabalho pode ser considerada satisfatória, pois nenhum deles excedeu este valor.

\section{Comportamento a flexão}

A inclusão de fibras nos compósitos proporcionou tendência de crescimento na resistência à flexão, até um teor ótimo, com posterior queda nesta propriedade. Isto ocorre porque, após certa taxa de polpa, a concentração volumétrica de fibras acarreta dificuldade de mistura e dispersão. No caso, os teores com maior resistência à flexão foram $6 \%$ para o compósito com polpa sem refino e $8 \%$ para o compósito com polpa refinada (Tabela 2).

A capacidade de absorver energia (tenacidade), medida pelo método do RILEM-1984, foi a propriedade mais sensível ao acréscimo de polpa. Quando o teor de polpa passou de 4 para $14 \%$, esta propriedade apresentou um aumento de 6 vezes para a polpa refinada e de aproximadamente 2,5 vezes para a polpa sem refino. O acréscimo de $14 \%$ no teor de polpa, em relação à matriz sem reforço, aumentou a deflexão na ruptura em aproximadamente 7 vezes para ambos os tipos de polpa. Esses resultados demonstram o potencial da polpa celulósica de bambu para utilização em painéis submetidos à flexão.

As percentagens de 14 e $16 \%$ de fibras promoveram notável ductilidade aos compósitos reforçados com polpa refinada e sem refino, porém se tem uma perda também considerável na resistência à flexão máxima, como se verifica nas Figura $8 \mathrm{~A} \mathrm{e} \mathrm{B,}$ respectivamente. A resistência à flexão e a capacidade de absorver energia são maiores para os compósitos com polpa refinada que para os com polpa sem refino, para todos os teores de reforço empregados.

Os compósitos com polpa refinada apresentam maiores valores para energia específica (tenacidade) e resistência à flexão, que os compósitos com polpa sem refino, para todos os teores de reforço utilizados. Isto se deve, provavelmente, ao maior número de fibras por unidade volumétrica da matriz, pois as fibras refinadas parecem apresentar maior relação de aspecto (L/D) devido ao processo de refinação, resultando numa superfície de fratura com maior número de fibras capazes de interceptar as fissuras; além disso, as fibras refinadas parecem ser mais resistentes, em razão do menor teor de lignina extraída pelo processo de refinação. 
Tabela 2. Propriedades mecânicas dos compósitos aos 28 dias

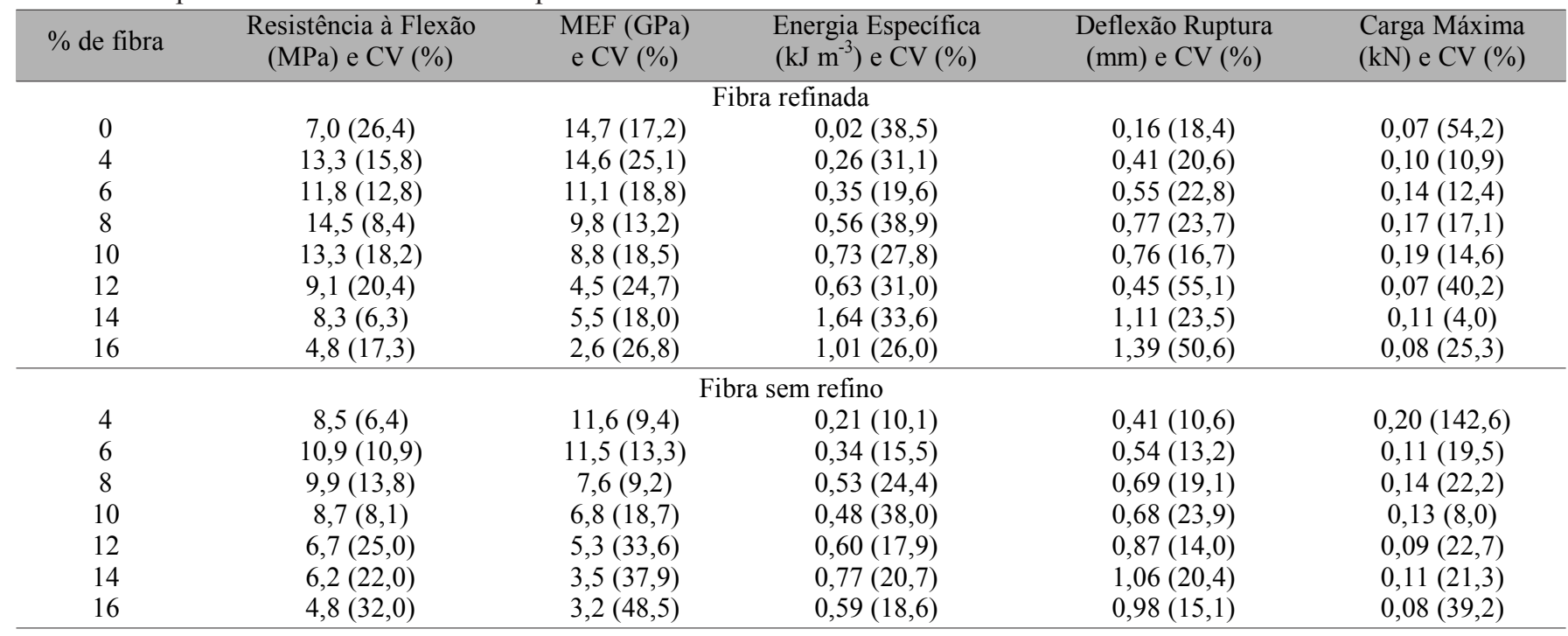

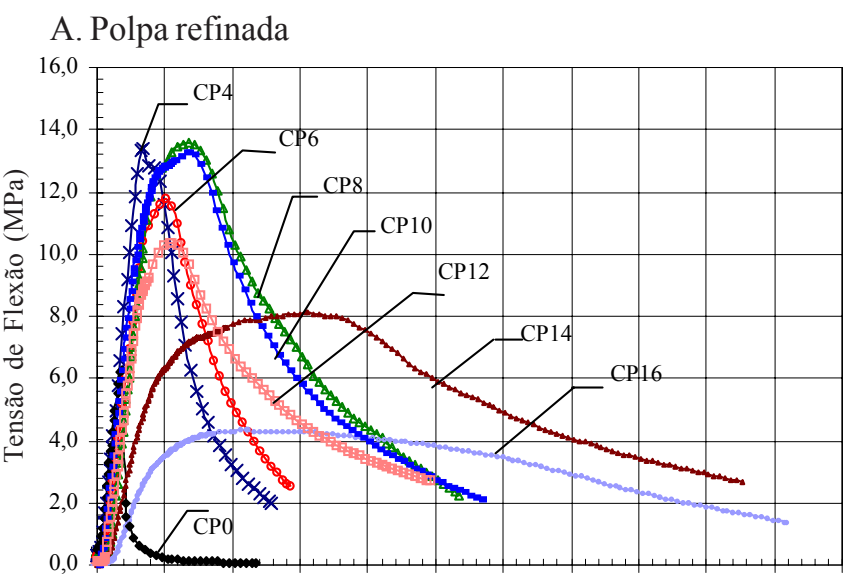

B. Polpa sem refinamento

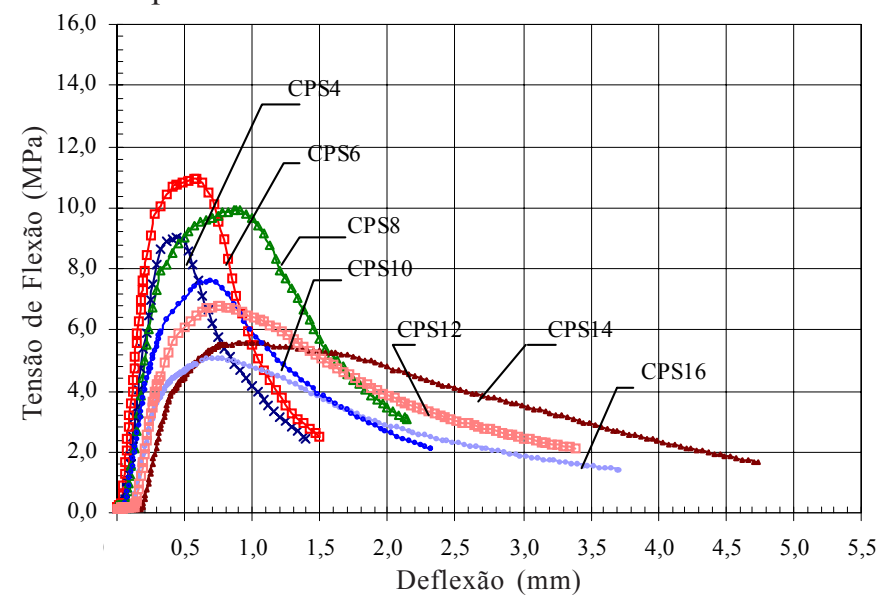

Figura 8. Tensão de flexão - deflexão dos compósitos com diferentes teores de polpa refinada (A) e sem refinamento (B)

A falha dos compósitos em flexão pode ocorrer por deslizamento da fibra da matriz, por perda de aderência, ou ruptura da fibra. As imagens obtidas no microscópio eletrônico de varredura mostram que a superfície de fratura dos compósitos com polpa refinada parece apresentar maior predominância de arrancamento das fibras (pull out), o que pode ser sugerido pelos vários pontos vazios destacados na Figura 9. Este fenômeno acarreta aumento na capacidade de absorver energia na flexão, o que foi confirmado nos ensaios. A ruptura dos compósitos com polpa sem refino parece ocorrer por fratura das fibras, ao invés do arrancamento, resultando assim numa capacidade menor de absorver energia (Figura 10).

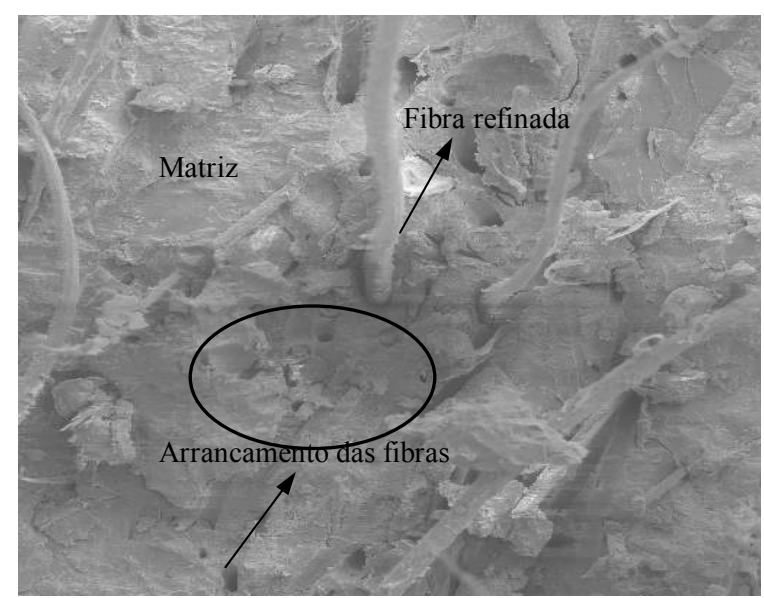

Figura 9. Imagem do compósito com $4 \%$ de polpa refinada obtida no $\mathrm{MEV}$, aumento de 200 vezes

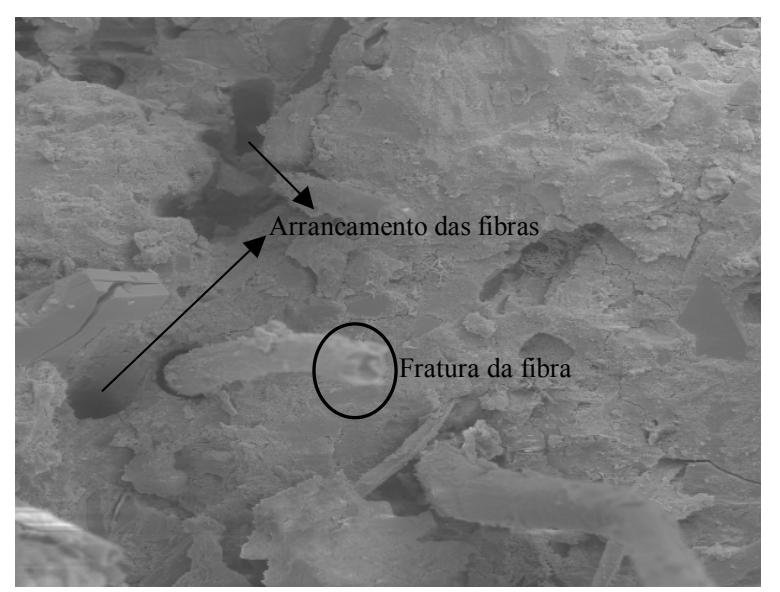

Figura 10. Imagem do compósito com $6 \%$ de polpa sem refino obtida no $\mathrm{MEV}$, aumento de 500 vezes 
As fibras sem refino têm superfície mais rugosa e isso pode ser motivo para elas apresentarem, aparentemente, maior aderência com a matriz, rompendo antes do escorregamento.

\section{Comportamento a compressão e a tração indireta}

A tensão correspondente ao início da propagação instável das fissuras, chamada tensão crítica, pode ser caracterizada como aquela equivalente ao valor máximo da deformação volumétrica que, no caso de concretos, ocorre a $75 \%$ da tensão máxima (Mehta \& Monteiro, 1994). Para os compósitos reforçados com $8 \%$ de polpa celulósica, isto ocorre a nível de tensão de $90 \%$ da última tensão, correspondente ao ponto A da Figura 11. O fim do trecho linear é mostrado pelo ponto $C$ na curva, estando este a um nível de tensão de 0,65 da resistência à compressão última $\left(\mathrm{f}_{\mathrm{cu}}\right)$. Este ponto caracteriza o aparecimento da primeira fissura. A não linearidade no início da curva de tensão-deformação axial se deve à acomodação do corpo-deprova na máquina de ensaio.

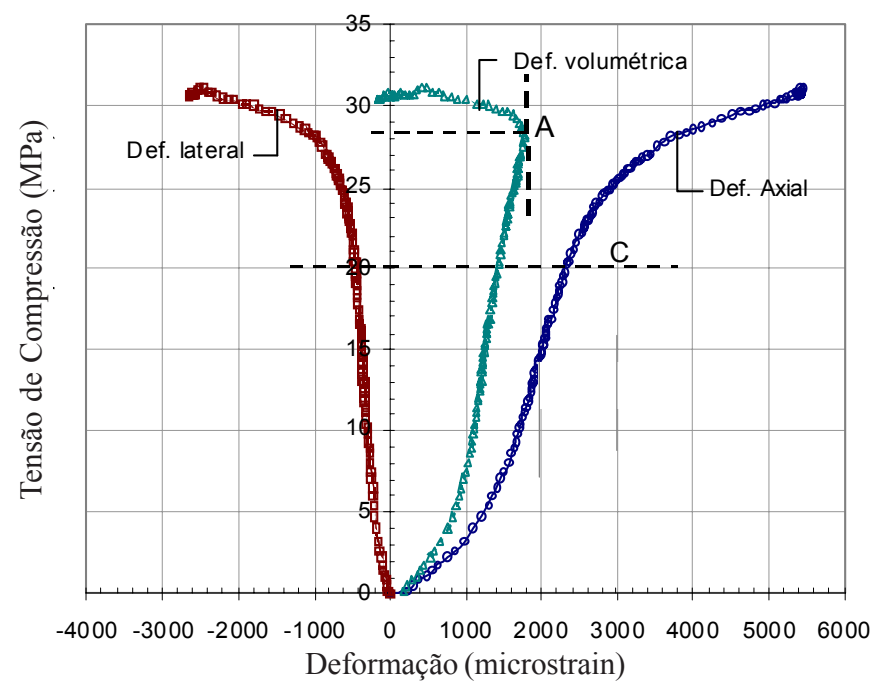

Figura 11. Tensão-deformação vertical, lateral e volumétrica no ensaio de compressão

As resistências médias e respectivos desvios-padrão foram de 26,3 e 3,8 MPa nos ensaios de compressão, e de 4,92 e 0,60 MPa nos de tração indireta, para os compósitos reforçados com $8 \%$ de polpa refinada, tendo sido ensaiados seis espécimes para cada propriedade.

A Figura 12 mostra as deformações que ocorreram vertical e horizontalmente, nas seções transversais externas dos corpos-de-prova cilíndricos submetidos ao ensaio de tração por compressão diametral. Vê-se que a deformação lateral ou horizontal foi da ordem de $60 \%$ da deformação vertical.

Verificou-se que, com o reforço de $8 \%$ de fibras refinadas em massa, a resistência à tração foi cerca de $20 \%$ da resistência à compressão, diferentemente da matriz isolada, cuja resistência à tração é de apenas 10 a $12 \%$ daquela resistência. Para a resistência à flexão, os compósitos com $8 \%$ de fibras refinadas apresentaram resistência cerca de 3 vezes maior que a resistência à tração, quando, para a matriz plena, essa relação não é maior que 1 vez.

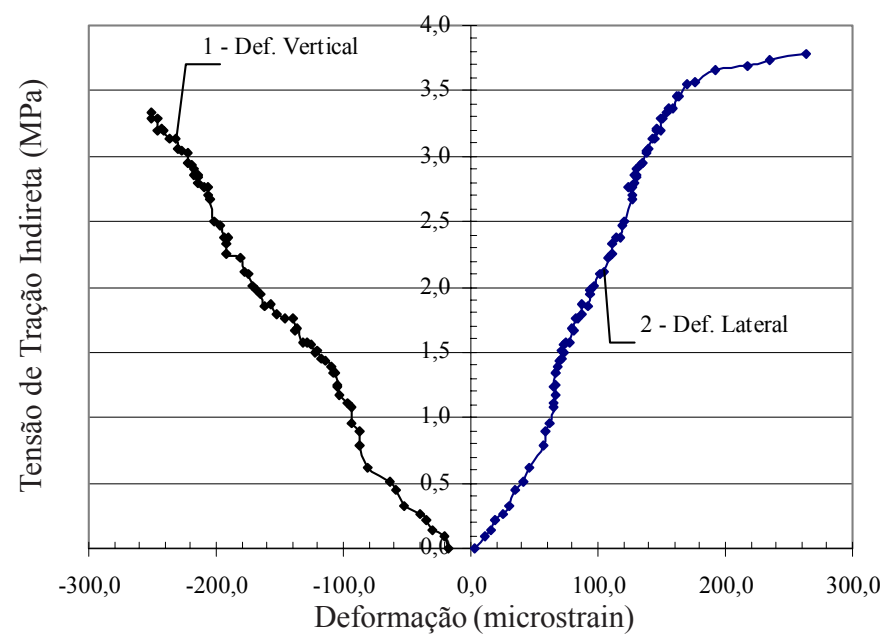

Figura 12. Tensão-deformação vertical e lateral no ensaio de tração por compressão diametral

Para os compósitos analisados neste trabalho, pode-se dizer que as matrizes cimentícias reforçadas com polpas de bambu poderão perfeitamente gerar produtos de larga aplicação na construção civil, uma vez estabelecidas as propriedades de longa duração e conduzidos estudos a respeito da durabilidade para peças expostas às intempéries.

\section{CONCLUSÕES}

1. A resistência à flexão apresentou tendência de crescimento com o aumento no teor de reforço até um ponto ótimo que, no caso da polpa refinada, foi de $8 \% \mathrm{e}$, para as polpas sem refino, de $6 \%$.

2. Teores de fibra acima desses valores acarretaram dificuldades de mistura e dispersão das fibras no compósito.

3. As fibras refinadas conduziram a compósitos de melhor performance que as fibras sem refino.

4. Na porcentagem ideal de $8 \%$, as fibras refinadas promoveram, em relação à matriz plena, uma resistência a flexão quase $110 \%$ maior e uma capacidade de absorver energia 28 vezes maior, quase quintuplicando a deformação na ruptura.

5. A incorporação de fibras aumentou significativamente a absorção e a porosidade aparente do compósito, acréscimo este ligeiramente superior no caso das fibras sem refino. Por sua vez, as densidades seca e úmida diminuíram proporcionalmente com o teor de fibras.

\section{AGRADECIMENTOS}

À CAPES, pela concessão da bolsa de Mestrado ao primeiro autor, e ao programa PROCAD da CAPES, FAPERJ e CNPq, pelo apoio financeiro, e ao colega Conrado Rodrigues, pela colaboração neste trabalho.

\section{LITERATURA CITADA}

ABNT - Associação Brasileira de Normas Técnicas. Telha de fibrocimento, tipo pequenas ondas. NBR - 12800. Rio de Janeiro, 1993. 12p. 
ABNT - Associação Brasileira de Normas Técnicas. Concreto - Ensaio de corpos-de-prova cilíndricos - NBR - 5739. Rio de Janeiro, 1994. 4p.

ABNT - Associação Brasileira de Normas Técnicas. Argamassa e Concreto - Determinação da resistência à tração por compressão diametral de corpos-de-prova cilíndricos - NBR - 7222. Rio de Janeiro, 1994. 8p.

Anjos, M.A.S. Compósito à base de cimento reforçado com polpa de bambu - caracterização física, mecânica e microestrutural. Rio de Janeiro: PUC, 2002. 96p. Dissertação Mestrado

ASTM - American Society for Testing and Materials - C 1185/ 96. Standard test methods for sampling and testing nonasbestos fiber-cement flat sheet, roofing and siding shingles and clapboards. New York, 1996, 7p.
Coutts, R.S.P.; Ni, Y. Autoclaved bamboo pulp fibre reinforced cement, Cement and Concrete Composites, [S.1.], v.17, p.99106, 1995.

Mehta, K.; Monteiro, J.P. Concreto: Estrutura, Propriedades e Materiais. 1. São Paulo: editora Pini, 1994. 573p.

RILEM Technical Committee 49 TFR, Testing methods for fibre reinforced cement-based composites, v.17, n.102, 15p., 1984.

Rodrigues, C.S. Mecânica da fratura de compósitos de matrizes rígidas 'argamassa' reforçados com fibras de sisal. Rio de Janeiro: PUC, 1999. 110p. Dissertação Mestrado

Smook, G.A. Handbook for pulp and paper technologists. Joint Committee of the Paper Industry, Canadá. 1989. 370p.

Swamy, R.N. Vegetable fiber reinforced cement composites - a false dream or a potential reality? In: International Symposium on Vegetable Plants and their Fibres as Building Materials, 2, Salvador, 1990, Proceedings. [S.1.], Chapman and Hall, p.3-9. 